\title{
REVIEW
}

\section{Treatment of tobacco dependence: integrating recent progress into practice}

\author{
Bernard Le Foll MD PhD, Tony P. George MD
}

\section{ABSTRACT}

Tobacco use is one of the leading preventable causes of death in developed countries. Adoption of approaches that have demonstrated efficacy to improve the treatment of tobacco dependence are critical to reduce the health consequences of tobacco use. We summarize the latest epidemiologic data on tobacco use, the mechanisms that underlie tobacco dependence, and advances in pharmacotherapy and nonpharmacologic interventions available for the treatment of tobacco dependence. Specifically, we discuss the use of nicotine replacement therapy, bupropion and varenicline in primary care settings.

Une version française de ce résumé est disponible à l'adresse www.cmaj.ca/cgi/content/full/I77/II/I373/DCI

CMAJ 2007;177(II):1373-80

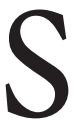
moking is currently responsible for the death of $\mathrm{I}$ in Io adults worldwide, or about 5 million deaths each year. Half of the 650 million people who smoke today will eventually be killed by tobacco, ${ }^{1}$ and this morbidity and mortality can be mostly avoided if people stop smoking. ${ }^{2}$ The prevalence of smoking varies greatly around the world. Over 4.5 million people are current smokers in Canada, representing $18 \%$ of the population aged 15 years and older. ${ }^{3}$ Smoking prevalence is still high in countries such as China and India (approximately 50\% and 30\% respectively among males) and is on the rise in developing countries. ${ }^{4}$ Consequently, tobacco use is one of the few causes of death that is increasing globally. ${ }^{4}$

In Canada and other Western countries, considerable progress has been made in decreasing tobacco use. Interestingly, there has also been a decrease in the quantity of tobacco smoked, as indicated by the number of cigarettes smoked per day (now I5.4 cigarettes on average per day among daily smokers in Canada, compared with I8.4 in I990) and by the increasing proportion of smokers who do not smoke daily. ${ }^{3}$ Tobacco use also differs between males and females, although the gap is narrowing. In Canada, males continue to smoke more than females overall, but there is currently no significant sex-related difference in smoking prevalence among adolescents. The prevalence of tobacco use among females is increasing. This trend is alarming, since the health consequences are now affecting women at high rates: in Canada, the prevalence of lung cancer among women is now higher than that of breast cancer.

\section{Determinants of tobacco use}

Tobacco dependence results from several closely interrelated factors - neurochemical, environmental and individual all of which must be taken into account for the successful treatment of tobacco dependence. . $^{1,5,6}$

\section{Neurochemical determinants}

Although tobacco smoke contains several substances, nicotine appears to be the critical reinforcing component of tobacco smoke. ${ }^{7-10}$ Therefore, for simplicity, we will consider here that nicotine is responsible for most of the effects of tobacco smoke in humans. A large body of evidence implicates $\alpha_{4} \beta_{2}-$ nicotinic acetylcholine receptors in the reinforcing effects of nicotine. ${ }^{11,12}$ The initial effect of nicotine is probably to activate $\alpha_{4} \beta_{2}$-nicotinic acetylcholine receptors located on dopamine neurons in the ventral tegmental area; however, it is likely that these receptors are rapidly desensitized, whereas nicotine produces a sustained effect on dopamine release in the nucleus accumbens (Figure I). According to the "dopamine hypothesis" of drug dependence, the increase in dopamine levels in the nucleus accumbens produced by drugs of abuse is critical to the drugs' ability to induce motivational and reinforcing properties. ${ }^{13}$ Although the nucleus accumbens plays a pivotal role in drug-seeking behaviour, the influence of the prefrontal cortex, the amygdala and the hippocampus (which, through the glutamate and $\gamma$-aminobutyric acid [GABA] neurons, mediate the drive to take drugs, the influence of drug-associated cues and the memory of drug taking) is critical (Figure I). Therefore, medications that act on glutamate or $\gamma$-aminobutyric acid systems probably hold the promise of reducing drug cravings or avoiding relapse. ${ }^{14}$ Several other promising approaches are currently under investigation. ${ }^{15-17}$

Tobacco withdrawal triggers a range of unpleasant and stressful signs and symptoms, ${ }^{18}$ including headache, nausea, constipation or diarrhea, falling heart rate and blood pressure, fatigue, drowsiness or insomnia, irritability, difficulty concentrating, anxiety, depression, increased hunger and energy in-

From the Translational Addiction Research Laboratory (Le Foll) and Addiction Psychiatry (George), Centre for Addiction and Mental Health, University of Toronto, Toronto, Ont. 
take, increased pleasantness of the taste of sweets, and tobacco cravings. Most withdrawal signs and symptoms peak 48 hours after quitting smoking and disappear completely in 6 months. Switching to a cigarette with a reduced nicotine content ${ }^{19}$ or ceasing the use of nicotine gum ${ }^{20,21}$ can also result in withdrawal syndrome. Administering nicotine through nicotine replacement therapy strongly decreases the intensity of withdrawal symptoms..$^{22,23}$ Therefore, the decrease in nicotine levels is assumed to be mainly responsible for the tobacco withdrawal symptoms. As with people addicted to other substances, the behaviour of smokers is controlled by both positive reinforcement (the desire to obtain nicotine) and negative reinforcement (the desire to decrease withdrawal symptoms).

Although nicotine acts like a typical drug of abuse, the risk of abuse of nicotine replacement therapy is low in naive patients. Therefore, nicotine appears to be addictive in humans only through the form of tobacco. The absence of dependence to pure nicotine in naive patients suggests that the speed of nicotine delivery to the brain through tobacco smoke may be ideal to initiate dependence properties. Another possible hypothesis is that other constituents of tobacco smoke that are inhaled along with nicotine may potentiate the reinforc- ing effects of nicotine; however, this hypothesis has not been validated in humans or nonhuman primates. ${ }^{8}$

\section{Environmental determinants}

As indicated by the strong impact of taxation and legislation to restrict tobacco use on the prevalence of smoking in Canada, environmental factors play a critical role in reducing tobacco use. Measures that limit the purchase of tobacco products and exposure to tobacco smoke should be widely implemented and expanded to sustain the reduction of tobacco use in Canada. Comprehensive tobacco control measures that are effective include increased taxation of tobacco products, consumer regulations, dissemination of information about tobacco products, legislation against advertising and sponsorship by tobacco companies, economic alternatives to tobacco production and smoking cessation programs. ${ }^{1,6,24,25}$ Canada was one of the first countries to ratify the World Health Organization's Framework Convention on Tobacco Control (www.who.int/tobacco/framework/en/) and has played a leadership role in implementing some of the measures, such as health warnings on cigarette packaging. Further steps are currently being implemented in various

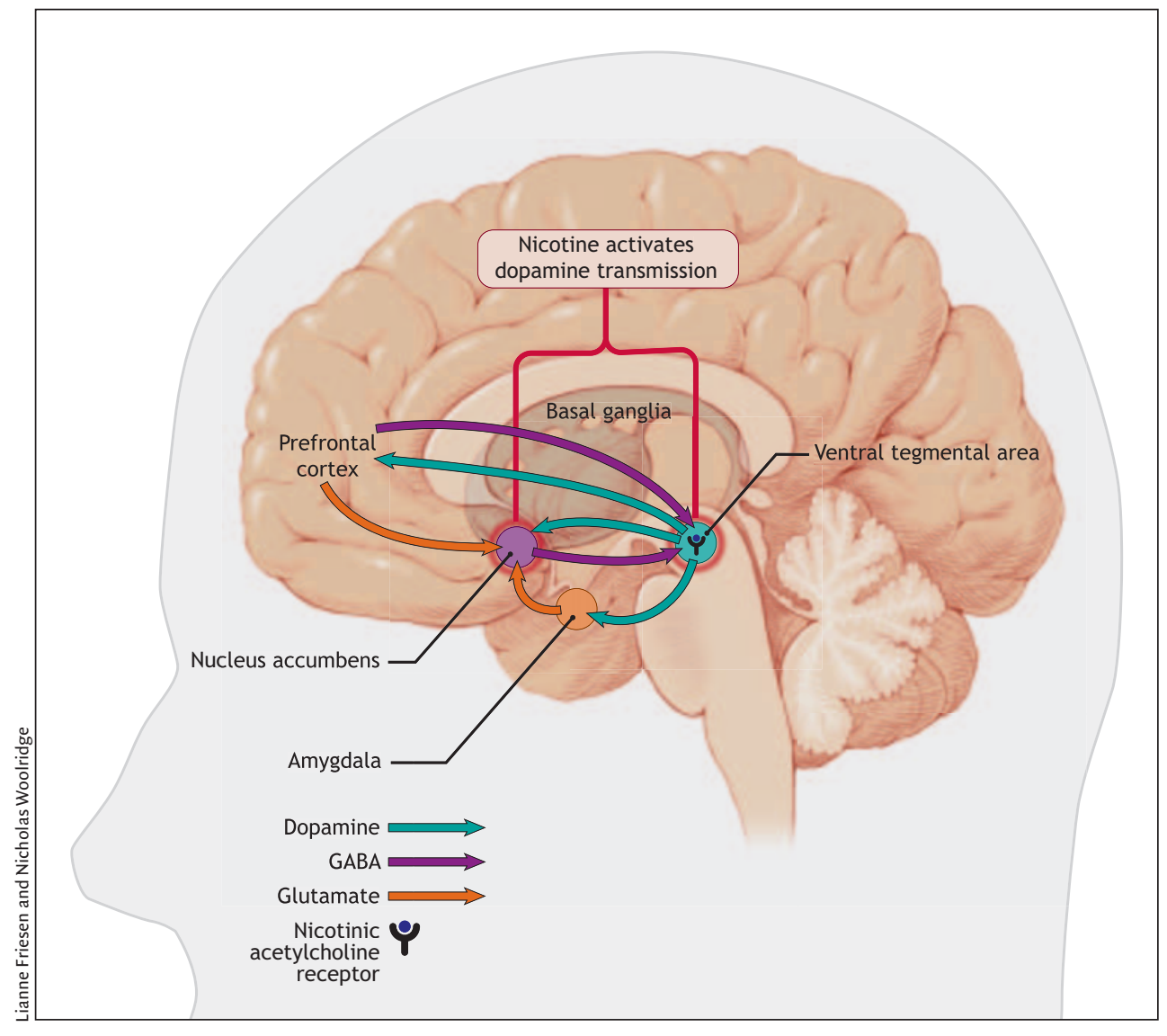

Figure 1: Areas in the brain involved in nicotine addiction. Nicotine stimulates nicotinic acetylcholine receptors located in the ventral tegmental area, which leads to the release of dopamine in the nucleus accumbens, an important step in the process of nicotine addiction. Neurons projecting from the prefrontal cortex and amygdala modulate the release of dopamine in the nucleus accumbens, which allows for control of these addictive behaviours. These regulatory pathways are comprised of glutamate and gamma-aminobutyric acid (GABA) neurons. 
provinces across Canada (www.otru.org/monitoring_reports .html). By implementing those measures ${ }^{26,27}$ it is possible to reduce tobacco use on a societal level and therefore facilitate change on an individual level.

Individuals have also become particularly sensitive to environmental stimuli, or cues, that have acquired motivational salience through repeated associations with self-administered nicotine. ${ }^{28}$ Tobacco-seeking, craving and relapse are well known to be triggered by these environmental stimuli. Moreover, the fact that these environmental situations cannot be avoided by most smokers (e.g., in the home or the work place) may explain the high rate of relapse observed among ex-smokers, as compared with people dependent on other drugs of abuse. The new regulations that restrict the use of tobacco in public places help to reduce the influence of these cues on behaviour and therefore help exsmokers to maintain their abstinence.

\section{Individual determinants}

Individuals are not at equal risk of tobacco dependence. An important and significant genetic component has been found to play a role in several aspects of smoking behaviour, such as the initiation and maintenance of smoking, the number of cigarettes smoked and the response to pharmacologic treatments. ${ }^{29,30}$ However, these results are too preliminary to be useful for tailoring treatments to individual smokers.

A strong link exists between tobacco use and the presence of psychiatric disorders such as schizophrenia, depression and comorbid drug addiction. Smoking rates are elevated 2to 3 -fold among people with such disorders compared with the general population. This high degree of comorbidity suggests that these conditions have shared neurobiologic and behavioural abnormalities. However, other explanations are possible, such as the fact that tobacco may be used to improve the psychiatric condition or to reduce the side effects of some psychiatric medications. Tobacco smoke contains chemical substances other than nicotine that inhibit monoamine oxidase $\mathrm{A}$ and $\mathrm{B}$ activity in the brain. ${ }^{31}$ These nonnicotinic effects that mimic the effects of antidepressant drugs may explain the increased risk of depression for 6 months or longer following smoking cessation. ${ }^{32}$

\section{Management of tobacco use and dependence}

Optimal management of tobacco use and dependence requires adequate evaluation of the patient and his or her environment. Since an estimated $70 \%$ of smokers see a physician each year, physicians have a substantial opportunity to influence smoking behaviour. ${ }^{33}$ Other health professionals (e.g., counsellors, nurses, dentists and pharmacists) can also play an important role in encouraging people to quit. The essential features of smoking cessation treatment have been described as the 5 As: ask about smoking at every opportunity, advise all smokers to stop, assess their willingness to stop, assist the smoker to stop and arrange follow-up (Figure 2). ${ }^{34,35}$ Success is often obtained only after several attempts. Therefore, health practitioners should adopt the same atti- tude as they would with other chronic disorders and should provide support over a long period. ${ }^{1,25,34}$ Any new treatment phase should be considered a therapeutic trial and its efficacy re-evaluated regularly.

As the first step, the health practitioner should systematically ask about tobacco use and advise the patient about the risks and about the availability of efficacious strategies to quit. The next step is to evaluate the patient's willingness to quit. If the person is not motivated, effective approaches (e.g., motivational interviewing) have been developed for the health practitioner to enhance the patient's motivation to quit.

For a patient who is motivated to quit, the goal of treatment is total abstinence, the only outcome that is associated with reduced health risks attributable to tobacco. The use of pharmacologic treatments as partial substitutes to reduce tobacco consumption and therefore morbidity or mortality (harm reduction) has been proposed, but this approach is still not validated..$^{36}$ Two approaches that have been proven efficacious for smoking cessation are pharmacotherapy and nonpharmacologic interventions..$^{34,37-41}$ The best results are obtained when the 2 approaches are combined, which was done during the clinical trials that evaluated the medications for smoking cessation. ${ }^{34,37-41}$ It is estimated that the use of pharmacotherapy can increase a patient's chance of initiating and maintaining abstinence 2 - to 3 -fold..$^{34,37-41}$ Thus, these treatments are clearly efficacious and should be used more extensively.

\section{Pharmacotherapy}

Three distinct types of pharmacotherapy have demonstrated their efficacy for smoking cessation and are available in Canada, the United States and most of Europe: nicotine replacement therapy, bupropion and varenicline (Table I). These treatments have been evaluated primarily in association with behavioural support during controlled clinical trials. ${ }^{34,38-40}$ To assess tobacco dependence, these trials used criteria from the DSM-IV (Diagnostic and Statistical Manual for Mental Disorders, $4^{\text {th }}$ edition) and the International Classification of Diseases; to assess the severity of tobacco dependence, they used the Fagerstrom Test for Nicotine Dependence. ${ }^{42}$ Smokers with moderate to severe tobacco dependence have been found to respond best to these 3 types of pharmacotherapy. However, no clear threshold exists that can help clinicians decide whether a patient will benefit from a particular pharmacotherapy, and there is no consensus on which type of pharmacotherapy should be used first. The health practitioner should make the decision on the basis of the patient's preference and the presence of contraindications (Table I).

Whichever pharmacotherapy is chosen, it should be used first as monotherapy, since there is no clear evidence for additive effects of combining pharmacotherapies. Combination therapies can be tested if monotherapy is not efficacious (Figure 2). Combinations of various forms of nicotine replacement therapy (e.g., patch and gum, patch and inhaler) have been tested, as has the combination of nicotine replacement therapy with bupropion..$^{43}$ More studies are needed in this area to guide prescribing. Other medications (nortriptyline, ${ }^{44}$ clonidine,${ }^{45}$ selegiline ${ }^{46}$ and rimonabant ${ }^{15}$ ) have been found to increase rates of smoking cessation significantly in some tri- 


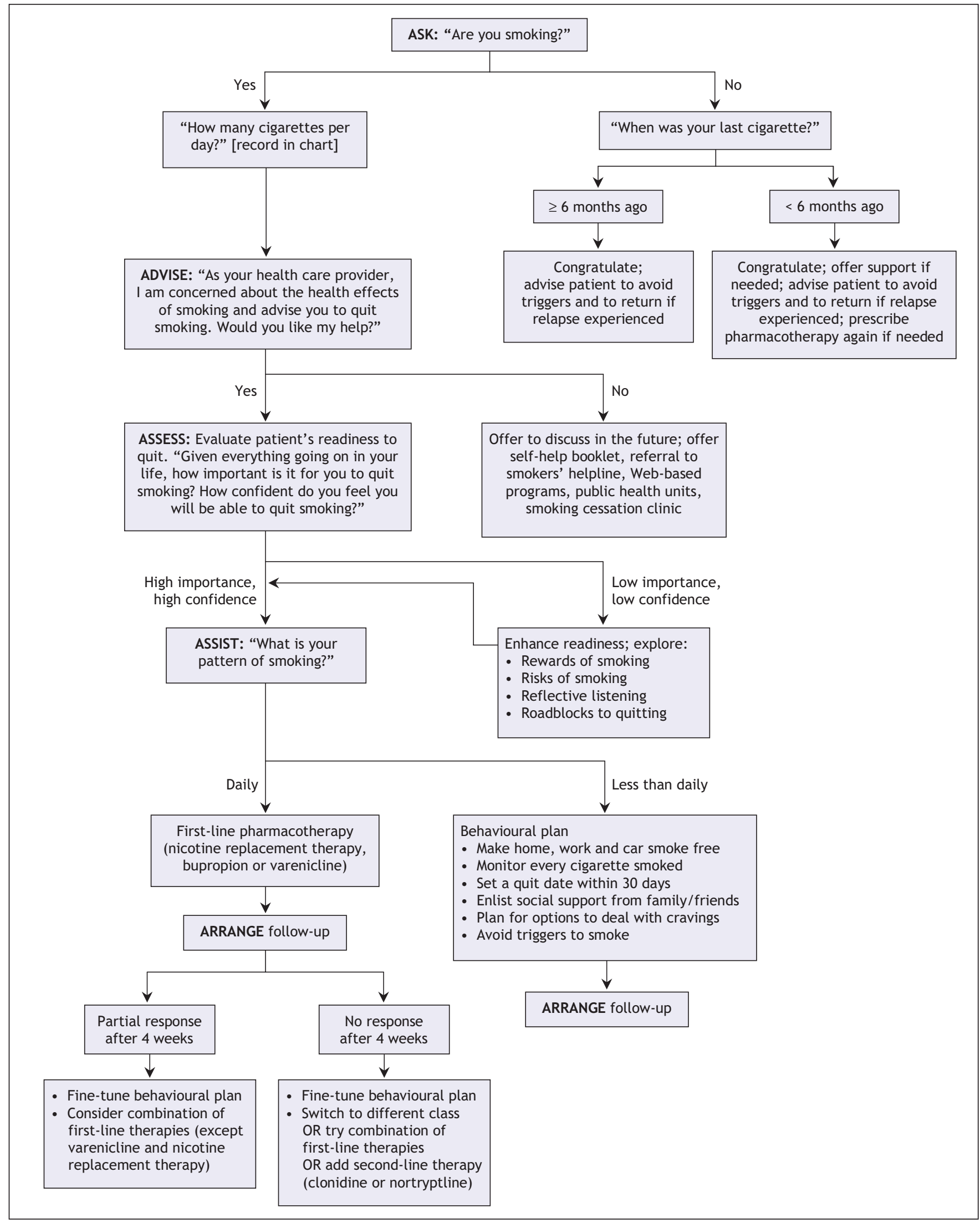

Figure 2: Algorithm for integrating a patient's smoking status and his or her readiness to quit. A comprehensive approach integrating assessment, behavioural interventions and pharmacologic treatment of tobacco dependence. 
als. However, at this point, only nortriptyline and clonidine could be considered as second-line medications in patients who do not respond to first-line medications ${ }^{34}$ (Figure 2). However, these 2 medications may not be effective in all patients, and their use is limited by side effects.

\section{Nicotine replacement therapy}

Nicotine replacement therapy alleviates nicotine withdrawal symptoms and likely reduces the desire to smoke. Several products with different pharmacokinetic profiles have been developed: the patch, gum, nasal spray, inhaler, tablet and lozenge. ${ }^{47}$ Most of these products are currently available in Canada. The patch provides a continuous source of nicotine over I6-24 hours. ${ }^{48,49}$ The other types of nicotine replacement therapy have a shorter duration of action, which allows patients to tailor their nicotine intake. Blood nicotine levels vary greatly between products because of the wide variability in pharmacokinetics and dose delivery. ${ }^{50}$ With nicotine gum and inhalers, blood nicotine levels peak within 20 minutes after use. Nasal sprays have shorter latencies of action, with blood nicotine levels peaking within ${ }^{-}$-10 minutes. ${ }^{51,52}$ No difference in efficacy has been demonstrated between products.

Ineffectiveness of nicotine replacement therapy is often due to improper use or insufficient dosage. Therefore, clinicians should give practical advice to their patients to obtain maximal efficacy. The dosage should be adjusted at the beginning of treatment if there are clinical signs of toxic effects (e.g., nausea insomnia, palpitations) or of insufficient dosage (i.e., persistence of severe withdrawal symptoms such as irritability, restlessness, anxiety, increased appetite and depressed mood). For this purpose, different products (patches, gum, inhaler or lozenges) may be associated with better tolerance in some smokers. If a patient finds one patch ineffective or intolerable, for example, it is sometimes useful to try an- other patch before switching to a different type of product or a different type of therapy. In addition, the dose should be adjusted depending on the patient's level of nicotine dependence. It is usually difficult to obtain an effective dose with nicotine gums or inhalers in patients who have a high level of dependence. Such patients may benefit from the use of several patches applied simultaneously on the skin or the use of a high-dose nicotine gum ( $4 \mathrm{mg}$ instead of $2 \mathrm{mg}$ ). ${ }^{47}$ However, clinicians should advise such patients not to start with more than 2 patches simultaneously to avoid overdose. Typically, the dose of nicotine replacement therapy is decreased progressively over 8-I2 weeks. ${ }^{53}$ For all nicotine replacement products taken by mouth, acidic drinks such as coffee and juice should be avoided for 15 minutes before product use, since they can reduce nicotine absorption.

Several studies have indicated that nicotine replacement therapy is well tolerated and does not increase the severity of cardiovascular disease and can even be used several days after myocardial infarction, for example..$^{54,55}$ These products can also be used safely by adolescents, although such use is still off label. Nicotine patches may be more effective than nicotine gum in this population. ${ }^{56}$ The use of nicotine replacement therapy during pregnancy is controversial, since the fetus may have harmful effects from nicotine exposure; however, there is consensus that nicotine replacement therapy is potentially less harmful to the fetus than tobacco smoke, which will expose the fetus not only to nicotine but also to other toxic components of tobacco smoke. ${ }^{57}$ Clinicians should first use a behavioural modification intervention with pregnant patients and introduce nicotine replacement therapy if the intervention is ineffective. The initial dose of nicotine should be similar to the dose the pregnant woman received when smoking. Intermittent-use formulations (gum, spray, inhaler or lozenge) are preferable because the total dose of nicotine delivered to the fetus will be

Table 1: First-line pharmacologic treatment of tobacco dependence

\begin{tabular}{|c|c|c|c|c|}
\hline Drug & Dose & Duration of treatment & Contraindications & Adverse effects* \\
\hline \multirow{5}{*}{$\begin{array}{l}\text { Nicotine } \\
\text { replacement } \\
\text { therapy }\end{array}$} & $\begin{array}{l}\text { Dose is adjusted to level of } \\
\text { nicotine dependence and is } \\
\text { decreased progressively over } \\
\text { treatment period }\end{array}$ & \multirow{5}{*}{$\begin{array}{l}\text { 8-12 weeks; can be } \\
\text { longer (up to } 1 \text { year) } \\
\text { for the prevention of } \\
\text { relapse }\end{array}$} & \multirow[t]{5}{*}{$\begin{array}{l}\text { Patch: allergy to constituent } \\
\text { of nicotine patch }\end{array}$} & $\begin{array}{l}\text { Patch: skin irritation, sleep } \\
\text { disturbance }\end{array}$ \\
\hline & Patch: $21-42 \mathrm{mg} / \mathrm{d}$ initially & & & $\begin{array}{l}\text { Gum or lozenge: mouth } \\
\text { irritation, sore jaw, } \\
\text { dyspepsia, hiccups }\end{array}$ \\
\hline & $\begin{array}{l}\text { Gum: 8-10 pieces ( } 2 \text { or } 4 \mathrm{mg} \\
\text { each) per day }\end{array}$ & & & \multirow[t]{3}{*}{$\begin{array}{l}\text { Inhaler: mouth and throat } \\
\text { irritation, cough }\end{array}$} \\
\hline & Inhaler: 4-6 puffs per day & & & \\
\hline & Lozenge: 9-20 lozenges per day & & & \\
\hline $\begin{array}{l}\text { Bupropion, } \\
\text { sustained } \\
\text { release (Zyban) }\end{array}$ & $\begin{array}{l}150 \mathrm{mg} / \mathrm{d} \text { for first } 3 \text { days, } \\
\text { then } 300 \mathrm{mg} / \mathrm{d}\end{array}$ & $\begin{array}{l}8 \text { weeks; can be } \\
\text { longer (up to } 1 \text { year) } \\
\text { for the prevention of } \\
\text { relapse }\end{array}$ & $\begin{array}{l}\text { Seizure, central nervous system } \\
\text { tumour, bipolar disorder, } \\
\text { alcohol withdrawal, } \\
\text { benzodiazepine withdrawal, use } \\
\text { of monoamine oxidase inhibitor, } \\
\text { anorexia, bulimia, liver disease }\end{array}$ & $\begin{array}{l}\text { Insomnia, seizure, } \\
\text { gastrointestinal } \\
\text { disturbance, jitteriness }\end{array}$ \\
\hline
\end{tabular}

*Most frequent adverse events. 
less than that with the patch. For all of these specific populations, a risk-benefit evaluation should be performed by a health professional. However, the evidence to date suggests that, in most situations, nicotine replacement therapy will provide some benefit.

\section{Bupropion}

Bupropion is an antidepressant with a dopaminergicnoradrenergic profile. The sustained-release formulation of the drug is efficacious for the treatment of nicotine dependence. ${ }^{44}$ Its effect on nicotine dependence appears to be separate from its antidepressant effect, since it is efficacious even in patients who have no depressive symptoms. Furthermore, bupropion can block nicotinic receptor function, an effect that may be critical for smoking cessation. Use of bupropion can double the chance of smoking cessation, offering an efficacy comparable to that of nicotine replacement therapy. ${ }^{44,47}$

Patients prescribed bupropion therapy should start taking the drug about I week before their quit date. ${ }^{44}$ The dose is usually $150 \mathrm{mg} / \mathrm{d}$ for the first 3 days and then $150 \mathrm{mg}$ twice daily. Bupropion is useful either as monotherapy or in combination with nicotine replacement therapy, and it may be used to prevent relapse. ${ }^{58}$ Several studies involving patients with schizophrenia, ${ }^{59,60}$ major depression ${ }^{61}$ and post-traumatic stress disorder ${ }^{62}$ suggest that sustained-release bupropion therapy is efficacious for treating tobacco dependence and safe for use in medication-stabilized outpatients.

The most serious side effect of bupropion therapy is seizure (frequency o.I\%), which suggests a careful respect for the contraindications of the product. The drug should be used cautiously in smokers with cardiovascular disease. Insomnia is the most frequent side effect, but patients can reduce its occurrence by taking the drug earlier in the day (a delay of 8 hours between pills must be respected).

\section{Varenicline}

Varenicline is a novel medication that is available for the treatment of tobacco dependence. ${ }^{63}$ It is a nicotinic receptor partial agonist, acting like an agonist or an antagonist depending on the state of activation of nicotinic receptors. Through its intrinsic partial activation of the $\alpha_{4} \beta_{2}$-nicotinic acetylcholine receptors, varenicline may elicit a moderate and sustained increase in mesolimbic dopamine levels, which would counteract the low dopamine levels encountered in the absence of nicotine during smoking cessation attempts. In addition, by competitively binding to the $\alpha_{4} \beta_{2}$-nicotinic acetylcholine receptors, the drug, as a partial agonist, protects against nicotine-induced dopaminergic activation in the event that the patient smokes. Thus, $\alpha_{4} \beta_{2}$ nicotinic receptor partial agonists may disrupt the reinforcing effects of nicotine and compensate for withdrawal symptoms.

Varenicline has been tested in several double-blind clinical trials involving smokers, and the results indicate a significant effect on smoking cessation rates. ${ }^{63}$ Its efficacy was found to be higher than that of bupropion (continuous abstinence $44 \%$ v. $29 \%$ for bupropion and $17 \%$ for placebo). However, no direct comparison with nicotine replacement therapy has

Table 2: Main nonpharmacologic interventions for the treatment of tobacco dependence and their estimated efficacy ${ }^{34,37}$

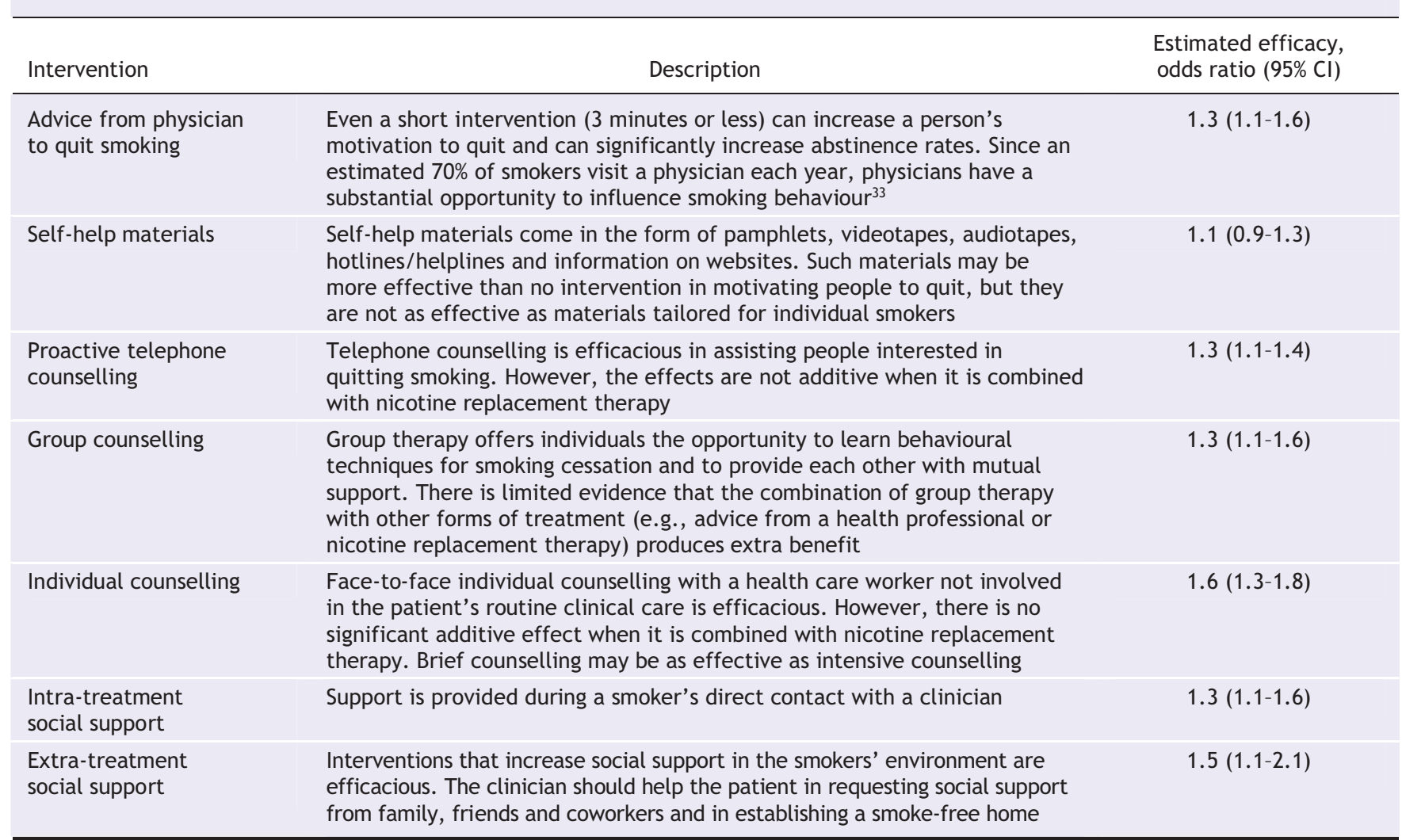

Note: $\mathrm{Cl}=$ confidence interval. 
been conducted, and so further trials are needed to determine the superiority of varenicline over the other first-line treatments available. Varenicline has also been found to be efficacious in preventing smoking relapse. ${ }^{64}$

Therapy is usually started at a dose of $0.5 \mathrm{mg}$ once daily for the first 3 days, $0.5 \mathrm{mg}$ twice daily for the next 4 days and then I mg twice daily, for a total duration of $\mathrm{I} 2$ weeks (lower dosage is indicated in cases of kidney disease or dialysis). There is evidence that prolonged treatment ( 24 weeks) may be efficacious ${ }^{64}$ and could be proposed for patients who are not ready to quit the medication at 12 weeks or who have had a relapse with shorter durations of treatment.

The main side effect of varenicline therapy is nausea, having occurred in about $30 \%$ of the patients in the clinical trials; however, it did not often prevent these patients from completing the trials. ${ }^{63,64}$

\section{Nonpharmacologic interventions}

Epidemiologic studies have indicated that the majority of successful attempts to quit smoking occur without direct medical assistance or without pharmacotherapy. ${ }^{25,65,66}$ Therefore, nonpharmacologic methods are feasible and their use should be encouraged, especially by people for whom medication use is problematic, such as adolescents and pregnant women. These smoking cessation attempts are encouraged by media or by the advice given to the patient to quit. Advising patients to quit, even just once, helps to double quit rates. To initiate as many cessation attempts as possible, practitioners should advise all of their patients who smoke to quit. Also, by using general motivational techniques or motivational enhancement therapy, the clinician promotes the patient's selfmotivational statements, and in turn the patient gains greater awareness of the problems associated with smoking. The goal is to motivate the patient to try to quit smoking.

During each patient contact, the clinician should ask about the person's smoking status and provide information on available treatments. A variety of interventions have been found to be efficacious, although their efficacy may not be additive with pharmacologic interventions (Table 2). A more intensive approach, such as behavioural and cognitive therapy, can be useful to help patients recognize, avoid and cope with difficult situations in which they are most likely to smoke. ${ }^{34,67,68}$ Coping strategies also target maladaptive thoughts to prevent relapse. Clinicians should inform patients of available community resources such as hotlines and helplines. They should also encourage patients to request social support from their family, friends and coworkers and to establish a smoke-free home.

Clinicians should encourage their patients who smoke to increase their physical activity level. Increased physical activity has been found to facilitate smoking cessation, most notably in women ${ }^{69}$ and may limit the weight gain that frequently follows smoking cessation. Most smokers will gain fewer than $5 \mathrm{~kg}$ after quitting, ${ }^{70-73}$ a negligible health threat compared with the risks associated with continued smoking. ${ }^{74}$ Since smoking cessation is the priority, aggressive treatment to fight the weight gain (e.g., strict dieting) are not recommended during a quit attempt. Once the patient has successfully quit smoking, he or she should be encouraged to maintain or adopt a healthy lifestyle, including exercise, eating plenty of fruits and vegetables, and limiting alcohol consumption. ${ }^{34}$ Nicotine replacement therapy and varenicline therapy do not reduce the weight gain following smoking cessation, and bupropion's effects in reducing such weight gain are modest. Rimonabant is a $\mathrm{CB}_{1}$ cannabinoid receptor antagonist currently available in Europe for the treatment of obesity and has been under investigation for the treatment of tobacco dependence. Although early results appear promising ${ }^{15}$ all of the risks and benefits have not been established and therefore the drug cannot be recommended at this time.

Most alternative therapies, such as acupuncture, mesotherapy, hypnosis and auriculotherapy, have not been found to present any favourable effect on smoking cessation outcomes. ${ }^{34,39}$

\section{Conclusion}

Tobacco use remains the leading preventable cause of death in developed countries. Since the majority of smokers see a physician each year, physicians have a substantial opportunity to influence smoking behaviour. Brief clinical interventions are effective and should follow the approach of the 5 As: ask about smoking at every opportunity, advise all smokers to stop, assess their willingness to stop, assist the smoker to stop and arrange follow-up (Figure 2). ${ }^{34,35}$ The health practitioner should ask about the smoking status of each patient and keep a record in the person's medical chart. Smoking behaviour is a chronic problem that requires long-term management. If the patient is not motivated to quit, strategies should be used to increase his or her willingness to quit, and information about problems associated with smoking should be provided. Pharmacotherapy with demonstrated efficacy should be prescribed. The presence of a psychiatric condition such as anxiety, depression or schizophrenia is not a contraindication for pharmacotherapy.

This article has been peer reviewed.

Competing interests: None declared for Bernard Le Foll. Tony George has received consultant and speaker fees from Pfizer and consult fees from Evotec and Sanofi for the development of smoking cessation medications.

Contributors: Both authors contributed to the conception and design, the drafting and the final approval of the article.

Acknowledgement: We thank Dr. Peter Selby for providing the draft of the algorithm and for his helpful comments.

\section{REFERENCES}

I. Tobacco Advisory Group of the Royal College of Physicians. Nicotine addiction in Britain: a report of the Tobacco Advisory Group of the Royal College of Physicians. London (UK): Royal College of Physicians of London; 2000.

2. Department of Health and Human Services. The health benefits of smoking cessation: a report of the Surgeon General. Washington (DC): US Public Health Service, Office on Smoking and Health; I990.

3. Canadian Tobacco Use Monitoring Survey (CTUMS) 2006. Ottawa: Health Canada; 2007. Available: www.hc-sc.gc.ca/hl-vs/tobac-tabac/research-recherche/stat /ctums-esutc/2006/index_e.html (accessed 2007 Oct 9).

4. Shafey O, Dolwick S, Guindon GE, editors. Tobacco control country profiles 2003 Atlanta: American Cancer Society; 2003. Available: www.who.int/tobacco/global _data/country_profiles/en/ (accessed 2007 Oct 23).

5. Department of Health and Human Services (DHHS). The health consequences of smoking. Nicotine addiction. Washington (DC): US Center for Health Promotion and Education, Office on Smoking and Health; I988. DHHS Publ no (CDC) 88-8406. 
6. Da Costa e Silva V, editor. Policy recommendations for smoking cessation and treatment of tobacco dependence. Geneva: World Health Organization; 2003.

7. Corrigall WA, Coen KM. Nicotine maintains robust self-administration in rats on a limited-access schedule. Psychopharmacology (Berl) I989;99:473-8.

8. Le Foll B, Goldberg SR. Nicotine as a typical drug of abuse in experimental animals and humans. Psychopharmacology (Berl) 2006;184:367-81.

9. Le Foll B, Wertheim C, Goldberg SR. High reinforcing efficacy of nicotine in nonhuman primates. PLOS ONE 2007;2(2): e230. doi:Io.I37I/journal.pone.0000230.

ro. Le Foll B, Goldberg SR. Nicotine induces conditioned place preferences over a large range of doses in rats. Psychopharmacology (Berl) 2005;178:48I-92.

II. Picciotto MR, Zoli M, Rimondini R, et al. Acetylcholine receptors containing the beta2 subunit are involved in the reinforcing properties of nicotine. Nature 1998;391:173-7.

I2. Tapper AR, McKinney SL, Nashmi R, et al. Nicotine activation of alpha4* receptors: sufficient for reward, tolerance, and sensitization. Science 2004;306:1029-32.

13. Wise RA. Brain reward circuitry: insights from unsensed incentives. Neuron 2002 36:229-40.

I4. Dani JA, De Biasi M. Cellular mechanisms of nicotine addiction. Pharmacol Biochem Behav 2001;70:439-46.

I5. Le Foll B, Goldberg SR. Cannabinoid $\mathrm{CB}_{1}$ receptor antagonists as promising new medications for drug dependence. J Pharmacol Exp Ther 2005;312:875-83.

I6. Fagerstrom K, Balfour DJ. Neuropharmacology and potential efficacy of new treatments for tobacco dependence. Expert Opin Investig Drugs 2006;15:107-I6.

I7. George TP, O'Malley SS. Current pharmacological treatments for nicotine dependence. Trends Pharmacol Sci 2004;25:42-8.

I8. Hughes JR, Gust SW, Skoog K, et al. Symptoms of tobacco withdrawal. A replication and extension. Arch Gen Psychiatry I99I;48:52-9.

I9. West RJ, Russell MA, Jarvis MJ, et al. Does switching to an ultra-low nicotine cigarette induce nicotine withdrawal effects? Psychopharmacology (Berl) I984;84:120-3

20. West RJ, Russell MA. Effects of withdrawal from long-term nicotine gum use. Psychol Med I985;I5:89I-3.

2I. Hughes JR, Hatsukami DK, Skoog KP. Physical dependence on nicotine in gum. A placebo substitution trial. JAMA I986;255:3277-9.

22. Hughes JR, Hatsukami DK, Pickens RW, et al. Effect of nicotine on the tobacco withdrawal syndrome. Psychopharmacology (Berl) 1984;83:82-7.

23. West RJ, Jarvis MJ, Russell MA, et al. Effect of nicotine replacement on the cigarette withdrawal syndrome. BrJ Addict 1984;79:215-9.

24. Jha P, Chaloupka FJ. Curbing the epidemic: governments and the economics of to bacco control. Washington: The World Bank; 1999.

25. US Department of Health and Human Services. Reducing tobacco use: a report of the Surgeon General. Atlanta: US Department of Health and Human Services, US Centers for Disease Control and Prevention, National Center for Chronic Disease Prevention and Health Promotion, Office on Smoking and Health; 2000.

26. Stephens T, Pederson LL, Koval JJ, et al. The relationship of cigarette prices and no-smoking bylaws to the prevalence of smoking in Canada. Am J Public Health I997;87:1519-2I.

27. Pierce JP, Gilpin EA, Emery SL, et al. Has the California Tobacco Control Program reduced smoking? JAMA I998;280:893-9.

28. O'Brien CP. Research advances in the understanding and treatment of addiction. Am J Addict 2003; I2(Suppl 2):S36-47.

29. Pianezza ML, Sellers EM, Tyndale RF. Nicotine metabolism defect reduces smoking. Nature $1998 ; 393: 750$.

30. Schnoll RA, Johnson TA, Lerman C. Genetics and smoking behavior. Curr Psychiatry Rep 2007;9:349-57.

3I. Fowler JS, Volkow ND, Wang GJ, et al. Inhibition of monoamine oxidase B in the brains of smokers. Nature I996;379:733-6.

32. Glassman AH, Covey LS, Stetner F, et al. Smoking cessation and the course of major depression: a follow-up study. Lancet 200I;357:1929-32.

33. Rigotti NA. Clinical practice. Treatment of tobacco use and dependence. N Engl J Med 2002;346:506-I2.

34. Fiore MC, Bailey WC, Cohen SJ, et al. Treating tobacco use and dependence. Clinical practice guideline. Rockville (MD): US Department of Health and Human Services, Public Health Service; 2000.

35. How to help your patients stop smoking: a National Cancer Institute manual for physicians. Bethesda (MD): US Department of Health and Human Services; I989.

36. Tverdal A, Bjartveit $\mathrm{K}$. Health consequences of reduced daily cigarette consumption. Tob Control 2006;15:472-80.

37. Lancaster T, Stead L, Silagy C, et al. Effectiveness of interventions to help people stop smoking: findings from the Cochrane Library. BMJ 2000;321:355-8.

38. West R, McNeill A, Raw M. Smoking cessation guidelines for health professionals: an update. Health Education Authority. Thorax 2000;55:987-99.

39. Le Foll B, Melihan-Cheinin P, Rostoker G, et al. Smoking cessation guidelines: evidence-based recommendations of the French Health Products Safety Agency. Eur Psychiatry 2005;20:43I-4I.

40. Work Group on Substance Use Disorders, Kleber HD, Weiss RD, Anton RF, et al Treatment of patients with substance use disorders, second edition. American Psychiatic Association. Am J Psychiatry 2006;163(Suppl):5-82

4I. Henningfield JE, Fant RV, Buchhalter AR et al. Pharmacotherapy for nicotine dependence. CA Cancer J Clin 2005;55:28I-99; quiz 322-3, 325.

42. Heatherton TF, Kozlowski LT, Frecker RC, et al. The Fagerstrom Test for Nictoin Dependence: a revision of the Fagerstrom Tolerance Questionnaire. Br J Addict I991;86:III9-27.

43. Jorenby DE, Leischow SJ, Nides MA, et al. A controlled trial of sustained-releas bupropion, a nicotine patch, or both for smoking cessation. N Engl J Med I999; 340:685-91.
44. Hughes JR, Stead LF, Lancaster T. Antidepressants for smoking cessation. Cochrane Database Syst Rev 2007;(I):CDoooo3I.

45. Gourlay SG, Stead LF, Benowitz NL. Clonidine for smoking cessation. Cochrane Database Syst Rev 2004;(3):CDoooo58.

46. George TP, Vessicchio JC, Termine A, et al. A preliminary placebo-controlled trial of selegiline hydrochloride for smoking cessation. Biol Psychiatry 2003;53:136-43.

47. Silagy C, Lancaster T, Stead L, et al. Nicotine replacement therapy for smoking cessation. Cochrane Database Syst Rev 2004;(3):CDoooI46.

48. Gries JM, Benowitz N, Verotta D. Importance of chronopharmacokinetics in design and evaluation of transdermal drug delivery systems. J Pharmacol Exp Ther I998;285:457-63.

49. Gourlay SG, Benowitz NL, Forbes A, et al. Determinants of plasma concentrations of nicotine and cotinine during cigarette smoking and transdermal nicotine treatment. Eur J Clin Pharmacol 1997;5I:407-I4.

50. Benowitz NL, Zevin S. Jacob Pr.Sources of variability in nicotine and cotinine levels with use of nicotine nasal spray, transdermal nicotine, and cigarette smoking. $\mathrm{Br}$ Clin Pharmacol I997;43:259-67.

51. Perkins KA, Sexton JE, Reynolds WA, et al. Comparison of acute subjective and heart rate effects of nicotine intake via tobacco smoking versus nasal spray. Pharmacol Biochem Behav 1994;47:295-9.

52. Schneider NG, Lunell E, Olmstead RE, et al. Clinical pharmacokinetics of nasal nicotine delivery. A review and comparison to other nicotine systems. Clin Phar macokinet $1996 ; 31: 65-80$.

53. Sims TH, Fiore MC. Pharmacotherapy for treating tobacco dependence: What is the ideal duration of therapy? CNS Drugs 2002;16:653-62.

54. Joseph AM, Norman SM, Ferry LH, et al. The safety of transdermal nicotine as an aid to smoking cessation in patients with cardiac disease. NEngl J Med 1996;335:1792-8.

55. McRobbie H, Hajek P. Nicotine replacement therapy in patients with cardiovascular disease: guidelines for health professionals. Addiction 200I;96:1547-5I.

56. Moolchan ET, Robinson ML, Ernst M, et al. Safety and efficacy of the nicotine patch and gum for the treatment of adolescent tobacco addiction. Pediatrics 2005; II5:e407-I4.

57. Dempsey DA, Benowitz NL. Risks and benefits of nicotine to aid smoking cessation in pregnancy. Drug Saf 2001;24:277-322.

58. Hays JT, Hurt RD, Rigotti NA, et al. Sustained-release bupropion for pharmacologic relapse prevention after smoking cessation. a randomized, controlled trial. Ann Intern Med 200I; $135: 423-33$

59. Evins AE, Cather C, Rigotti NA et al. Two-year follow-up of a smoking cessation trial in patients with schizophrenia: increased rates of smoking cessation and reduction. JClin Psychiatry 2004; 65: 307-II; quiz 452-3.

6o. George TP, Vessicchio JC, Termine A, et al. A placebo controlled trial of bupropion for smoking cessation in schizophrenia. Biol Psychiatry 2002;52:53-6I.

6r. Chengappa KN, Kambhampati RK, Perkins K, et al. Bupropion sustained release as a smoking cessation treatment in remitted depressed patients maintained on treatment with selective serotonin reuptake inhibitor antidepressants. J Clin Psychiatry 200I;62:503-8.

62. Hertzberg MA, Moore SD, Feldman ME, et al. A preliminary study of bupropion sustained-release for smoking cessation in patients with chronic posttraumatic stress disorder. JClin Psychopharmacol 200I;21:94-8.

63. Cahill K, Stead LF, Lancaster T. Nicotine receptor partial agonists for smoking cessation. Cochrane Database Syst Rev 2007; (I):CDoo6ro3.

64. Tonstad S, Tonnesen P, Hajek P, et al. Effect of maintenance therapy with varenicline on smoking cessation: a randomized controlled trial. JAMA 2006;296:64-7I.

65. Giovino GA. Epidemiology of tobacco use in the United States. Oncogene 2002;2I 7326-40.

66. Giovino GA, Henningfield JE, Tomar SL, et al. Epidemiology of tobacco use and dependence. Epidemiol Rev 1995;17:48-65

67. Lancaster T, Stead LF. Individual behavioural counselling for smoking cessation. Cochrane Database Syst Rev 2000;(2):CDoor292.

68. Le Foll B, Aubin HJ, Lagrue G. [Behavioral and cognitive therapy to break the smoking habit. Review of the literature]. Ann Med Interne (Paris) 2002;153(3 Suppl): $\mathrm{IS}_{32-40}$

69. Ussher MH, Taylor AH, West R, et al. Does exercise aid smoking cessation? A systematic review. Addiction 2000;95:199-208.

70. Perkins KA. Weight gain following smoking cessation. J Consult Clin Psycho I993;6I:768-77

7I. Perkins KA, Sexton JE, DiMarco A, et al. Acute effects of tobacco smoking on hunger and eating in male and female smokers. Appetite 1994;22:149-58.

72. Froom P, Melamed S, Benbassat J. Smoking cessation and weight gain. J Fam Pract I998;46:460-4.

73. Klesges RC, Winders SE, Meyers AW, et al. How much weight gain occurs following smoking cessation? A comparison of weight gain using both continuous and point prevalence abstinence. J Consult Clin Psychol I997;65:286-9I.

74. Burnette MM, Meilahn E, Wing RR, et al. Smoking cessation, weight gain, and changes in cardiovascular risk factors during menopause: the Healthy Women Study. Am J Public Health i998;88:93-6.

Correspondence to: Dr. Bernard Le Foll, Head, Translational Addiction Research Laboratory, Centre for Addiction and Mental Health, 33 Russell St., Toronto ON M5S 2SI; fax 4I6 595-6922; bernard_lefoll@camh.net 